\title{
FATTY ACID RELATIONSHIPS OF THE NORMAL AND EFFERENTIECTOMIZED BOVINE EPIDIDYMIS
}

\author{
T. T. TURNER AND A. D. JOHNSON
}

Department of Animal Science, University of Georgia, Athens, Georgia 30601, U.S.A.

\section{(Received 12th Fune 1973)}

The total lipid content of spermatozoa during several stages of maturation has been studied by Grogan, Mayer \&. Sikes (1966) in the boar, by Setchell, Scott, Voglmayr \& Waites (1969) in the ram, and by Lavon, Volcani \& Danon (1970) in the bull. These authors have noted a general decrease of total lipid as spermatozoa undergo maturation. Scott, White \& Annison (1961) analysed volatile fatty acids and long chain free fatty acids of ejaculated spermatozoa from the bull, ram, rabbit, fowl, dog, stallion and man. Their conclusion was that long chain free fatty acid and volatile fatty acid concentrations were too low to be of any value to the sperm cell after ejaculation. These authors did not investigate the levels or possible uses of fatty acids before ejaculation. In a later report, Scott, Voglmayr \& Setchell (1967) recorded that the fatty acids found in highest concentration in testicular and ejaculated spermatozoa were $16: 0,18: 2$ and 18:0 (the fatty acid notation is that of Ahrens and co-authors, 1959). There are apparently no reports of the fatty acid composition of either epididymal spermatozoa or epididymal tissue.

The present study was undertaken in order to determine the fatty acid composition of five different zones of the normal and efferentiectomized bovine epididymis.

The methods described by Turner \& Johnson (1973) were used when the epididymides of five mature bulls were unilaterally ligated at the efferent ductules and tissue samples were obtained. The five epididymal zones sampled were the proximal and distal caput epididymidis, the corpus epididymidis and the proximal and distal cauda epididymidis (Zones 1 to 5 , respectively). Tissue samples were rapidly frozen following excision and remained frozen until analysis.

The fatty acids of these tissue samples were extracted and methylated using a method described by Fleeger, Bishop, Gomes \& VanDemark (1968). The residue was redissolved in $0.1 \mathrm{ml}$ chloroform before analysis by gas-liquid chromatography. Separation of methyl esters was accomplished in a coiled glass chromatography column $(1.8 \mathrm{~m} \times 4.4 \mathrm{~mm})$ packed with $15 \%$ HI-EEF-1AP on Chromosorb-W (80 to $100 \mathrm{mesh}$ ). The injection port, column and flame ionization detector temperatures were $210^{\circ}, 200^{\circ}$ and $210^{\circ} \mathrm{C}$, respectively. Identification of methyl esters was based on retention times shown by injection of a known standard containing methyl esters of the following fatty acids: $8: 0,10: 0,12: 0,13: 0,14: 0,14: 1,15: 0,16: 0,16: 1,17: 0,18: 0,18: 1,18: 2$, $18: 3,20: 0,20: 1,20: 4,21: 0,22: 0,22: 1,24: 0$ and $24: 1$. 
Quantification of peaks was by triangulation. All peaks were calculated on the percentage of total chromatograph peak area. Peaks that were less than $1.0 \%$ of the total area were reported uniformly as $<1.0$. Data from this study were subjected to least squares analysis of variance followed by Duncan's multiple range test.

Data from this study with significant differences are presented in Table 1. The values given are the percentage composition of total sample for the individual fatty acids listed. In this study, the major fatty acids found were 16:0, 18:1, 18:0, 18:2 and 14:0, respectively (all $>5 \%$ ). The secondary class of fatty acids was made up of 20:4, 16:1, 24:0, 22:0 20:0 and 15:0, respectively $(>1 \%,<5 \%)$. All fatty acids with a chain length of less than 14:0 were less than $1 \%$ of the total sample, as were $17: 0,18: 3,20: 1,22: 1$ and $24: 1$.

Table 1. The fatty acid composition of five zones of the bovine epididymis

\begin{tabular}{c|c|c|c|c|c}
\hline \multirow{3}{*}{ Fatty acid } & \multicolumn{5}{|c}{ Epididymal zones } \\
\cline { 2 - 6 } & 1 & 2 & 3 & 4 & 5 \\
\hline $14: 0$ & $3 \cdot 46$ & $3 \cdot 11$ & $4 \cdot 35$ & $6 \cdot 54^{*}$ & $7 \cdot 10^{*}$ \\
$16: 0$ & $31 \cdot 51$ & 34.50 & $43 \cdot 20^{*}$ & $34 \cdot 90$ & $32 \cdot 33$ \\
$18: 0$ & $16 \cdot 80^{* *}$ & $12 \cdot 66$ & $10 \cdot 54$ & $13 \cdot 39$ & $16 \cdot 66^{* *}$ \\
$18: 1$ & $21 \cdot 81^{* *}$ & $18 \cdot 22^{* * *}$ & $16 \cdot 42$ & $12 \cdot 79$ & $12 \cdot 59$ \\
$22: 0$ & $0 \cdot 85$ & $1 \cdot 16$ & $0 \cdot 62$ & $2 \cdot 61^{*}$ & $1 \cdot 59$ \\
\hline
\end{tabular}

* Statistically significant $(P<0.05)$ between zones.

** Statistically significant $(P<0.01)$ between zones.

Considering the mean values of control and ligated tissues within zones, there were no significant differences in fatty acids with two exceptions. The values in ligated tissue for 16:1 in Zone 2 were significantly lower $(P<0.05)$ than in control tissues, and the values for 17:0 in Zone 4 were significantly higher $(P<0 \cdot 05)$ in ligated tissues. Due to this general absence of significant differences, the values, given by zone, for the percentage composition of the fatty acids shown in Table 1 reflect the average value found for that fatty acid within that zone in both ligated and control tissues.

These data indicate that efferentiectomy of the bovine epididymis causes little difference in the relative fatty acid composition of the epididymal tissue. The absence of significant differences between the normal and sperm-free epididymides suggests that the fatty acid percentages in the spermatozoa and in the tissue of the epididymal duct are relatively the same.

The overall relationship of one fatty acid to another appears to be similar to that of most other mammalian tissues. The major fatty acids found in this study seem to correspond with those found to exist in ejaculated spermatozoa by Scott et al. (1967) and in the testis by Johnson, Gomes \& VanDemark (1971).

Several fatty acids were significantly higher in the percentage composition of the total sample in a particular zone (Table 1). No other fatty acids studied showed significant differences between zones or treatments, nor were there significant trends for any of the fatty acids to increase or decrease in percentage composition of the sample as consecutive zones were considered. 
Some of the fatty acids tended to increase in percentage progressively down the zones (i.e. 14:0, 15:0, 20:0 22:1 and 24:0) and others tended to decrease (i.e. $16: 1,18: 1$ and $24: 1$ ) but these trends, while quantitatively recognizable, were not statistically significant.

There was a significant difference in the contribution of some fatty acids to particular areas of the epididymis, though these differences were not always associated with a trend. The values for 18:0 and 18:1, both major fatty acids, were significantly higher $(P<0.01)$ in the caput epididymidis. The corpus epididymidis was significantly higher $(P<0.05)$ in 16:0, another major fatty acid. The cauda epididymidis was significantly higher $(P<0.05)$ in the major fatty acids, 14:0 and 18:0, and in 22:0, a fatty acid of the second class. This information suggests that, at the least, the major fatty acids $(18: 0,18: 1,16: 0$, $14: 0$ ) have a significant affinity for particular zones and it seems possible that the fatty acid contribution to particular zones is higher for a functional reason. If lipids are utilized by epididymal spermatozoa as suggested by Turner \& Johnson (1971), these fatty acids may be needed at a specific site for proper maturation of the epididymal spermatozoa. Fatty acid composition, for instance, has been shown to influence cell membrane permeability (Scott et al., 1967). Cold shock, a condition more easily induced in ejaculated spermatozoa than in testicular spermatozoa, is thought to be related to cell membrane permeability. It is possible, therefore, that susceptibility to cold shock is the result of a necessary fatty acid relationship. If this is the case, it is also possible that fatty acid relationships in the epididymis influence other aspects of sperm physiology that are possibly related to membrane permeability. Overall sperm metabolism and sperm capacitation are two factors which may be affected in such a manner.

\section{REFERENCES}

Ahrens, E. H., Insull, W., Hirsch, J., Stoffel, W., Peterson, M. L., Farquhar, J. W., Miller, T. \& Tromasson, H. J. (1959) The effect on human serum lipids of a dietary fat, highly unsaturated but poor in essential fatty acids. Lancet, i, 115.

Fleeger, J. L., Bishop, J. P., Gomes, W. R. \& VanDemark, N. L. (1968) Testicular lipids: effect of unilateral cryptorchidism on fatty acids on testicular phospholipids and triglycerides. $\mathcal{7}$. Reprod. Fert. 12, 431 .

Grogan, D. E., Mayer, D. T. \& Sikes, J. D. (1966) Quantitative differences in phospholipids of ejaculated spermatozoa and spermatozoa from three different levels of the epididymis of the boar. 7. Reprod. Fert. 12, 431.

Johnson, A. D., Gomes, W. R. \& VanDemark, N. L. (1971) Testicular lipids. IV. Effect of unilateral and bilateral cryptorchidism on the fatty acids of esterified cholesterol in the rat and rabbit. 7. Reprod. Fert. 25, 425.

LAvon, U., Volgani, R. \& Danon, D. (1970) The lipid content of bovine spermatozoa during maturation and aging. 7. Reprod. Fert. 23, 215.

Scott, T. W., Voglmayr, J. K. \& Setchell, B. P. (1967) Lipid composition and metabolism in testicular and ejaculated ram spermatozoa. Biochem. f. 102, 456.

Scott, T. W., Whitr, I. G. \& Annison, E. F. (1961) Fatty acids in semen. Biochem. 7. 78, 740.

Setchele, B. P., Scott, T. W., Voglmayr, J. K. \& Waites, G. J. H. (1969) Characteristics of testicular spermatozoa and the fluid which transports them into the epididymis. Biol. Reprod. 1, 40.

Turner, P. C. \& Johnson, A. D. (1971) Epididymal lipid of the rat with and without testicular contribution. F. Reprod. Fert. 27, 249.

Turner, T. T. \& Johnson, A. D. (1973) The metabolic activity of the bovine epididymis. I. Utilization of glucose and fructose. J. Reprod. Fert. 34, 203. 